\title{
PITO: objeto de aprendizagem apoiando à reflexão pedagógica do professor $^{1}$
}

\author{
Alexandre Ramos Araujo ${ }^{2}$ - UFRGS - alexandreraraujo@yahoo.com.br \\ Ana Angélica Pereira Fernandes ${ }^{3}$ - UFRGS - ana.angelica@ usb.org.br \\ Vânia Ben Premaor ${ }^{4}$ - UFRGS - vaniaben@ gmail.com \\ Paulo Francisco Slomp ${ }^{5}$ - UFRGS - slomp@ufrgs.br \\ Flávio Luis Barbosa Nunes ${ }^{6}$ - CEFET-Pelotas-RS - flavio@ cefetrs.tche.br \\ Aline Vicharra Berro ${ }^{7}$ - UFRGS - alinevichara@ yahoo.com.br
}

Resumo: Apresentamos neste artigo a criação e o desenvolvimento do objeto de aprendizagem As Aventuras de Pito. Nosso objetivo é proporcionar aos educadores em formação, na modalidade a distância, possibilidades à expressão de idéias e reflexões sobre suas práticas pedagógicas, valorizando a construção do conhecimento. A metodologia adotada é qualitativa, com base num estudo de caso. Para coleta de dados utilizamos um questionário aberto e informações obtidas no fórum disponibilizado aos participantes. Na análise e interpretação da experiência verificamos que, num primeiro momento, ocorreram reflexões sobre aspectos periféricos. Após o aprofundamento das questões, percebemos uma tomada de consciência das práticas pedagógicas, por parte dos professores.

Palavras-chave: Objeto de aprendizagem, reflexão, prática pedagógica.

Abstract: We present in this article the creation and the development of the learning object the Adventures of Pito. Our objective is to provide to the educators in formation, in the distance learning modality, pedagogical possibilities to the expression of ideas and reflections on its pedagogical practices, valuing the construction of knowledge. The adopted methodology is qualitative, on the basis of a case study. For the collection of data we use an open questionnaire and information gotten in the available forum to the participants. In the analysis and interpretation of the experience we verify that, at a first moment, reflections occur on peripheral aspects. After the deepening of the questions, we notice a greater conscience of the pedagogical practices by the teachers.

Keywords: Learning object, reflections, pedagogical practice.

\section{Introdução}

Atualmente, nos deparamos com diversas situações onde as tecnologias sinalizam mudanças em várias dimensões de nossa vida. No campo da educação, o contexto não é diferente, porém as tecnologias de informação e comunicação (TICs) não

\footnotetext{
${ }^{1}$ Trabalho realizado como conclusão do Seminário Produção e Avaliação de Materiais Pedagógicas para a Educação a Distância, sob a orientação das professoras doutoras Rosane Aragón de Nevado (PPGEDU) e Marie Jane Soares Carvalho (PPGIE).

${ }^{2}$ Professor da rede privada de ensino.

${ }^{3}$ Mestranda da Faculdade de Educação da UFRGS.

${ }^{4}$ Doutoranda em Ciencias de la Educación pela Universidad Católica Argentina - Santa María de los Buenos Aires UCA, Argentina. Colaboradora do Projeto Alfa/Miforcal da Università cà Foscari di Venezia, Itália.

${ }^{5}$ Professor da Faculdade de Educação da UFRGS.

${ }^{6}$ Mestrando da Faculdade de Educação da UFRGS

${ }^{7}$ Mestranda da Faculdade de Educação da UFRGS.

V. 4 № 2, Dezembro, 2006
} 
mudam necessariamente a relação pedagógica. As TICs, tanto servem para reforçar uma visão conservadora, individualista, quanto uma visão progressista.

Segundo Moran (1995), a pessoa autoritária utilizará o computador para reforçar o seu controle sobre os outros. Por outro lado, uma mente aberta, interativa, participativa, encontrará nas tecnologias ferramentas e meios que ampliam a interação.

$\mathrm{O}$ processo de aprendizagem mediado por recurso informatizado tem suscitado vários questionamentos, tanto relacionados à dimensão pedagógica na utilização e aplicação como tecnologia informacional.

Diante de tais situações, entende-se que não se trata de usar as TICs a qualquer custo, pois elas por si não nos darão garantias no processo educativo. Faz-se necessário reconstruir a prática pedagógica mais adequada à evolução da vida e do mundo. Ao contrário, teremos apenas cartilhas eletrônicas revestidas de modernidade, porém com concepções centradas no pensamento linear, reducionista e instrucionista.

O contexto tecnológico da sociedade do conhecimento torna a aprendizagem, ao longo da vida do indivíduo, um imperativo de sobrevivência. Assmann (1998) propõe que, a educação não pode se resumir a informações acumuladas, mas sim na competência em continuar aprendendo, pois educar é fazer experiências de aprendizagem pessoal e coletiva.

É imprescindível refletir sobre a formação do educador, o qual desempenha um papel relevante no processo de ensino. Há várias modalidades em que a formação é possível. Mencionaremos neste estudo a modalidade a distância que, em algumas situações, apesar das técnicas e métodos sofisticados, continuam utilizando-se de materiais pedagógicos aprisionando a mente, a inteligência e a criatividade dos alunos.

O foco principal deste trabalho é a construção de um objeto educacional fundamentado numa concepção de educação, a qual prioriza a construção do conhecimento, onde o professor em formação possa se sentir ativo, e não como mero receptor ou reprodutor passivo de conceitos prontos e estáticos.

$\mathrm{O}$ objeto de aprendizagem foi testado com quinze alunos do primeiro semestre do Curso de Pedagogia em EAD da UNIDERP - INTERATIVA - Universidade para o Desenvolvimento do Estado e da Região do Pantanal. Para fins de análise e interpretação dos dados, utilizamos as informações contidas nos registros dos fóruns da própria ferramenta do objeto de aprendizagem, disponibilizado como complemento a um questionário com respostas abertas.

Através da análise dos dados constatamos que, num primeiro momento, as reflexões ocorreram sobre aspectos mais periféricos, que foram se transformando no decorrer das interações registradas nos fóruns, levando ao aprofundamento das questões trabalhadas e indicando uma tomada de consciência das suas ações, enquanto professores.

Este artigo está organizado da seguinte maneira: na seção 2 abordamos o material pedagógico em EAD; na seção 3 tratamos da concepção e construção do objeto de aprendizagem As Aventuras de Pito; na seção 4 realizamos a análise a respeito da testagem do objeto e reflexão sobre os resultados; e na seção 5 as considerações finais.

\section{O Material Pedagógico em EAD}

Nos programas de educação a distância os materiais impressos conquistaram um espaço hegemônico como instrumento de que dispõem os docentes para a realização do ensino. Não dá-se somente na modalidade a distância, ocorre também de forma marcante no sistema presencial.

Nas propostas de educação a distância, muitos aspectos contribuíram para que as 
ferramentas tecnológicas conquistassem um espaço relevante. Mas, várias delas continuaram a reforçar a concepção pedagógica apresentada nos antigos materiais, ou seja, modificaram apenas a roupagem. Permaneceram as velhas práticas, onde as informações são repassadas de forma estática.

O uso de diferentes mídias nos cursos on-line, como é o caso do hipertexto e da hipermídia, favorece a construção de um conhecimento extremamente versátil. Entretanto, tão importante quanto a diversidade de materiais é o projeto pedagógico de sua utilização e funcionalidade no âmbito educacional, (Mondragón 2006; Alava 2002). Os cursos on-line estão associados a uma série de facilidades, (Ben, 2004; Constantino, 2002) oferecendo ao usuário, em maior ou menor grau, de acordo com o objetivo da aplicação: edição de documentos, navegação pelo sistema, acesso multiusuário distribuído, interface interativa com o usuário através do grupo, da troca, da leitura, etc.

Faz-se necessário revisar esta modalidade de estudo, de forma que a aplicação das novas tecnologias traga o máximo de benefício aos usuários e ao processo educacional, incorporando as mudanças necessárias aos novos tempos, pois, segundo Martínez (1988) não estamos numa época de mudanças, estamos numa mudança de época.

Uma questão deve ser destacada: qual a compreensão de educação que temos, quais projetos queremos construir? $\mathrm{O}$ material pedagógico não tem uma função independente da sua concepção a respeito de como ocorre o processo de aprendizagem. Conforme Neder (1999), todo o material pedagógico deve ser pensado e concebido a partir de uma proposta delineada num projeto político de formação.

\section{A Concepção e Construção do Objeto de Aprendizagem As Aventuras de Pito}

Com o propósito de motivar aos educadores em formação, na modalidade a distância, novas possibilidades na expressão de idéias e de reflexões sobre suas práticas pedagógicas, foi desenvolvido o objeto de aprendizagem As Aventuras de Pito, a partir da concepção de Jean Piaget, sobre a ocorrência da construção do conhecimento.

Para Piaget (1987) o sujeito aprendiz é concebido como um ser dinâmico, que a todo momento interage com a realidade, operando ativamente com objetos e pessoas. Essa interação no ambiente faz com que construa estruturas mentais. A interação é um conceito fundamental na compreensão do processo de construção do conhecimento, pois o conhecimento não acontece a partir do sujeito e nem do objeto, mas exatamente na interação entre os dois. Piaget (1987, p. 386) expõe:

Por outras palavras, as relações entre o sujeito e o seu meio consistem numa interação radical, de modo tal que a consciência não começa pelo conhecimento dos objetos nem pelo da atividade do sujeito, mas por um estado indiferenciado; e é desse estado que derivam dois movimentos complementares, um de incorporação das coisas ao sujeito, o outro de acomodação às próprias coisas.

Sobre a importância das interações, Palloff e Pratt (2003, p. 27) destacam:

(...) fundamentais aos processos de aprendizagem são as interações entre os próprios estudantes, as interações entre os professores e os estudantes e a colaboração na aprendizagem que resulta de tais interações. 
Assim, as interações podem ser consideradas como a chave no processo de aprendizagem.

A partir das idéias acima expostas, o grupo planejou e implementou o objeto de aprendizagem, como uma ferramenta de apoio, capaz de permitir ao professor em formação refletir sobre sua prática pedagógica, comparando-a com outras situações vividas ou imaginadas. Possibilitando o registro desse processo através de um questionário com perguntas abertas e a sua posterior discussão num fórum.

O objeto de aprendizagem utiliza como estratégia a apresentação de uma história fictícia e solicita que os professores opinem a respeito dos acontecimentos. Depois disso, é apresentado o convite para que sejam realizadas comparações com problemas existentes no contexto escolar. Desta forma, pretendemos que o posicionamento inicial seja o mais espontâneo possível e desvinculado do ambiente profissional. Ou seja, o educador em formação se manifestará sobre um tema, o qual em princípio, não está relacionado com o ambiente escolar, portanto não se relaciona com sua auto-imagem profissional.

Pito é o personagem principal da história, sendo apresentado como uma criatura curiosa, ele gosta de aventuras e novas descobertas. Numa de suas andanças, como mostra a figura 1, encontra Beleléu, um artista que tem andado tristonho, pois um dia o seu líder trouxe uma grande inovação: o aparelho "avaliômetro". Através do aparelho foi detectado, as obras de arte produzidas pelos artistas locais não possuíam a qualidade esperada. Na tentativa de resolver o problema, foi consultado o Dr. Achismo, o qual indicou que cada artista usasse um óculos especial. Ao contrário do imaginado por Beleléu, além de não acabar com a tristeza trouxe mais problemas ao grupo.

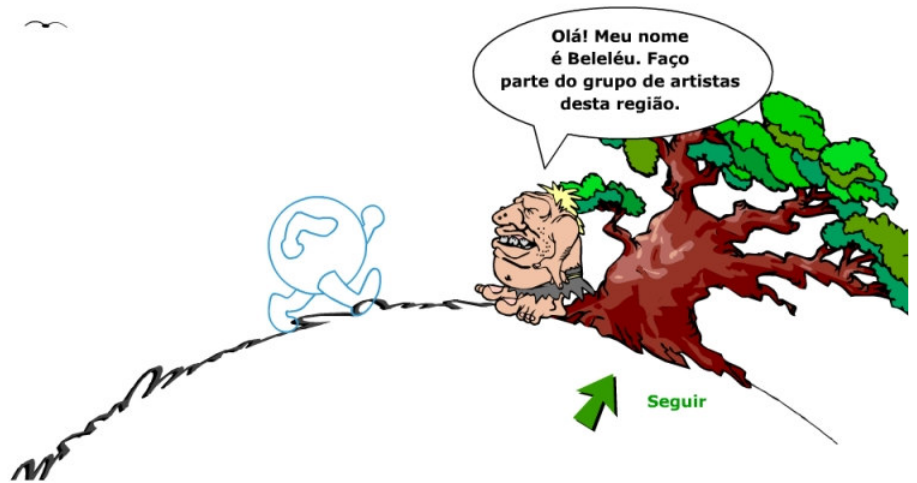

Figura 1 - O encontro entre Pito e Beleléu

Conforme a figura 2, o professor/aluno é convidado a fazer parte da história, ajudando o Beleléu a encontrar soluções criativas, resolvendo os problemas causados pelos óculos especiais utilizados por cada artesão. 


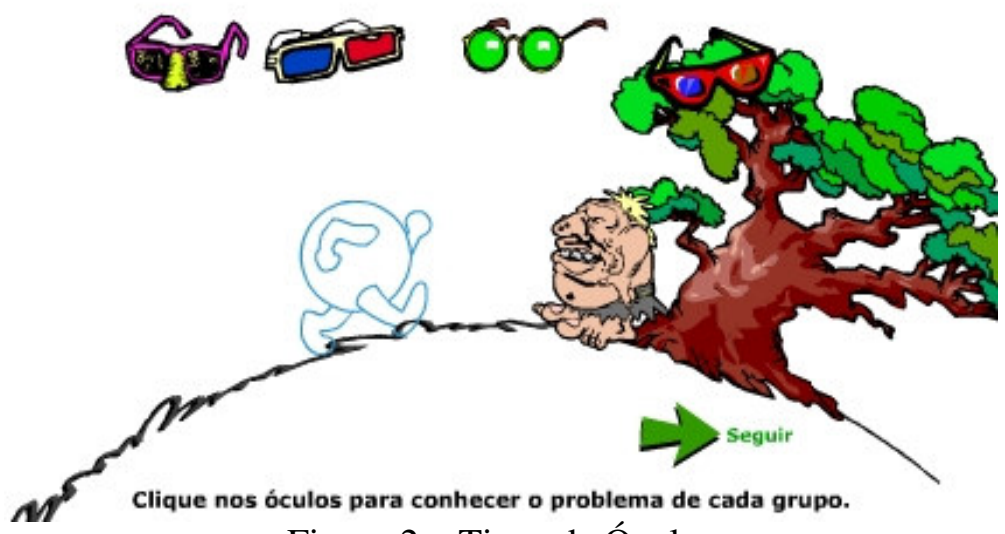

Figura 2 - Tipos de Óculos

A seguir são apresentados quatro tipos de óculos especiais, cada qual com disfunção específica, sendo que referem-se a problemas apresentados na história definida pelo professor.

Ao escolher um dos problemas, o aluno é convidado pelo Pito a registrar suas soluções, ler e comentar as reflexões registradas pelos colegas, conforme figura 3.

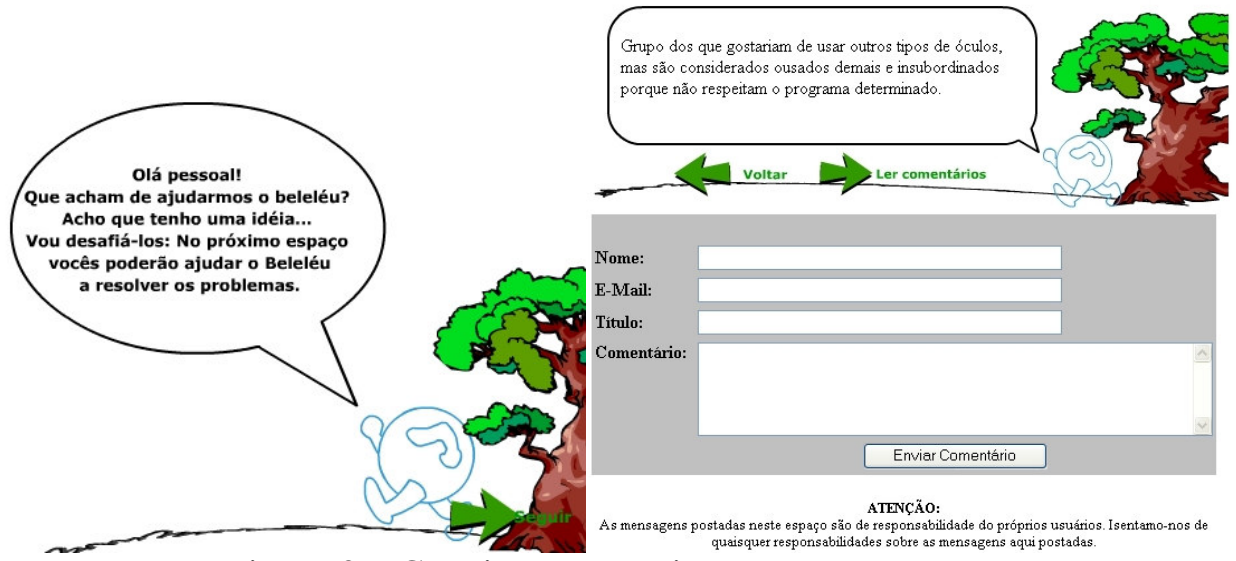

Figura 3 - Convite para Registrar suas Propostas

O fórum de discussão é alimentado pelos registros, dando início às interações entre os participantes e proporcionando espaço de reflexão. Na figura 4 apresentamos uma das telas com os títulos dos registros. 


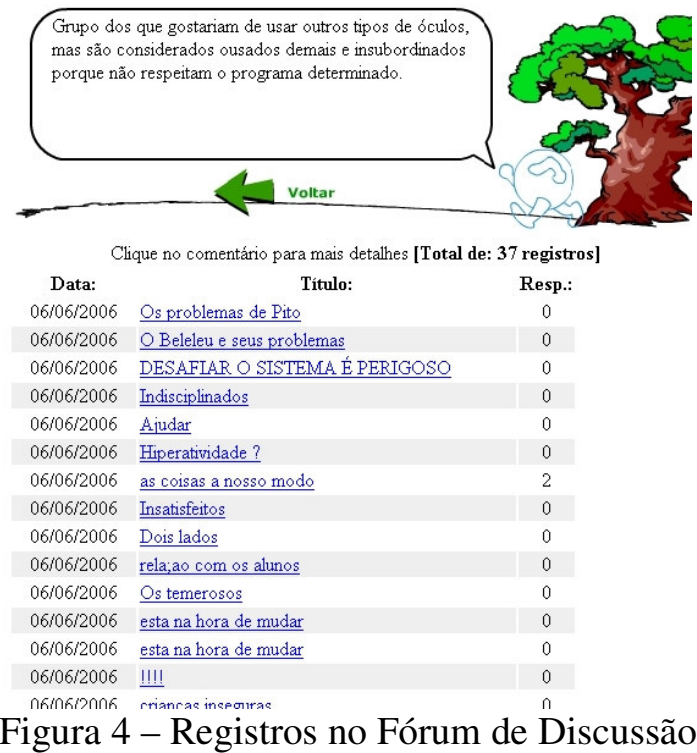

No desenvolvimento desta ferramenta utilizamos a linguagem ActionScript na realização das animações. Na implementação do fórum adaptamos um script PHP desenvolvido por Lauro Assis Lima de Brito, o qual se encontra disponível: www.phpbrasil.com além do banco de dados MySQL.

Utilizada de forma isolada, As Aventuras de Pito, não modificará a forma de pensamento e ação dos professores em formação. Mas, como ferramenta de apoio, pode contribuir na reflexão a respeito do trabalho docente.

Atualmente, As Aventuras de Pito não está disponível para o público, porém em breve pretendemos oferecer essa ferramenta gratuitamente. No momento, estamos realizando algumas melhorias, as quais se fizeram necessárias após as testagens. Uma delas, o aluno poderá ler o que seus colegas postaram após ele mesmo postar a sua contribuição. Será necessário melhorar o módulo do administrador, onde os problemas associados poderão ser substituídos ou alterados. Estão previstas ampliações, como por exemplo, o oferecimento de endereços webs de textos, figuras e vídeos, os quais estejam relacionados às questões apresentadas na história fictícia.

\section{Testagem do Objeto e Análise dos Resultados}

A metodologia adotada nesta pesquisa é qualitativa, com base num estudo de caso. O instrumento utilizado na coleta de dados e registro de informações foi um questionário com perguntas abertas e as informações contidas nos registros dos fóruns, da própria ferramenta de apoio. A testagem do objeto de aprendizagem As Aventuras de Pito trouxe pontos relevantes, os quais nos fazem refletir sobre a eficácia da produção de materiais pedagógicos, na formação de professores a distância. Nossa questão norteadora: $O$ objeto de aprendizagem As Aventuras de Pito, desenvolvido para programas de formação em EAD, proporciona um ambiente que privilegia reflexão e a expressão de idéias referentes à prática pedagógica dos educandos?

A população alvo da testagem foi de quinze participantes, são precedentes do grupo de alunos do curso de pedagogia em EAD da UNIDERP - INTERATIVA. São professores em exercício, onde o tempo de serviço oscila entre 4 meses e 20 anos.

A partir dos registros apresentados no questionário quanto às questões $1,2,3$, a respeito da clareza do material utilizado, facilidade de leitura, informações nas telas e praticidade de uso e manipulação, 13 dos participantes responderam que sim e 2 
disseram que não.

$\mathrm{Na}$ questão 4, sobre outro ponto a destacar no material apresentado, 7 professores não responderam. Dos demais, 4 disseram que a história fictícia é objetiva, clara, engraçada e simples; 2 responderam que o material possui fácil compreensão e é bem elaborado; 2 disseram que leva a reflexão e 3 perguntaram o porquê de um óculos em branco e seu objetivo.

As respostas da questão 5, sobre o que mais chamou atenção no material, 11 professores enfatizaram o aspecto da interação entre as pessoas, suas diferenças, a ajuda através de sugestões, a solidariedade e 3 salientaram o aspecto da interação com o leitor e os problemas nos óculos. Uma participante manifestou que é "um recurso do computador como ferramenta de trabalho na EAD".

Na questão 6, os 10 participantes não ofereceram sugestões de alterações. Os demais sugeriram que seria viável oferecer mais detalhes da história; os personagens mais atraentes, coloridos. A história poderia prosseguir com outros problemas para o Pito resolver.

O objeto foi testado em dois momentos. Num não estabelecendo relações com a prática docente e no outro sim. Observamos através da participação no fórum, que os sujeitos estabeleceram relações com o cotidiano como mostra o exemplo a seguir: "Esse grupo me lembra das pessoas que queriam ser diferentes das outras não seguindo regras e se vestindo de maneira escandalosa, como punks e roqueiros".

No segundo momento da aplicação foi solicitado o estabelecimento de relações com o contexto escolar e um dos participantes se posicionou da seguinte maneira: "Costumo ouvir continuamente dos meus colegas da escola a frase que diz que o aluno tem que se adaptar ao professor. Eu acredito e sempre defendo a idéia que cada pessoa tem o seu modo de pensar e devemos respeitá-lo. Infelizmente, ainda percebemos dentro de escolas aquele professor que se acha o certo em tudo, se algum dia algum aluno apresentar uma opinião contrária ao seu comportamento é de grande indignação".

Percebemos, diante dos registros no fórum, que os participantes atribuem grande importância ao papel desempenhado pelo indivíduo no contexto escolar, seja professor, aluno ou outro. Nos registros podemos ler:

Participante 1 - Infelizmente na última reunião pedagógica na minha escola ainda ouvi a frase "a gente faz, faz e tudo continua do mesmo jeito". Achei isto o cúmulo. Cada dia procuro fazer coisas novas na minha aula para que meus alunos aprendam e acredito na mudança. Se cada um fizesse e acreditasse nos seus feitos, o mundo e as coisas seriam melhores.

Participante 2 - Aqueles alunos que não querem nada com nada, acham que estudar é perda de tempo, só estão ali porque o pai quer e está pagando, qualquer proposta, a qual a professora propor para uma atividade vai dar sempre na mesma.

Participante 3 - Acredito que, as pessoas desde pequenas devem dar a sua opinião, dizer se aquilo que está sendo proposto lhes agrada ou não, o importante é a participação de todo, obtendo um resultado final satisfatório.

Podemos classificar a manifestação do participante 1 como um pronunciamento, onde o sujeito se coloca no lugar de professor. Já no registro do participante 2, o lugar ocupado foi o de aluno, através da empatia. Estas duas tendências foram observadas ao longo de todos os registros nos fóruns.

Os lugares diferentes assumidos pelos participantes podem indicar uma posição pessoal, a respeito da aptidão em mudar as práticas pedagógicas. Aqueles que se colocam na posição de alunos, através da empatia, podem estar mais dispostos a inovar suas práticas, pois entendem que os professores possuem condições de mudar o cotidiano na sala de aula. Já os participantes que apontaram ser os alunos, os quais 
devem mudar a sua postura, podem indicar certa resistência a mudar suas práticas pedagógicas, pois colocaram os problemas apenas nos alunos, como se não influenciasse diretamente entre a rejeição dos alunos e a forma de trabalho utilizada pelo professor.

Outro fator relevante foi a oportunidade concedida aos professores em formação de exporem suas idéias sobre o assunto abordado. No relato confirmamos: "o que mais me chamou atenção foi pelo fato de nós podermos expressar o que sentimos ao ler, e ao fato de atender as realidades, pois hoje em dia, existem muitas "crianças" com esses tipos de comportamentos diferentes um dos outros".

Segundo estudos realizados por Becker $(2001 ; 2003)$, a fala é um instrumento de troca entre os sujeitos. Nas palavras do autor ela é sempre ação sobre alguma ação anterior, mesmo que essa ação anterior seja também ela, alguma fala. E, salienta que a fala é, por excelência, construtora de conhecimento - como forma ou estrutura e como conteúdo - e constitutiva do sujeito.

Com a análise constatamos que, o objeto de aprendizagem As Aventuras de Pito, criou possibilidades ao professor em formação de refletir sobre sua atuação, enquanto educador. Onde seu envolvimento não ocorreu de forma restrita, no papel de um mero expectador, em que o conhecimento é transmitido de forma pronta e acabada e sim para atuar como protagonista no processo de conhecer.

\section{Considerações Finais}

Neste trabalho constitui-se como objetivo relatar a experiência de construção e testagem do objeto de aprendizagem As Aventuras de Pito. O objeto de aprendizagem, não possui um fim em si mesmo. Ou seja, não iremos atribuir a ele a responsabilidade de propiciar a construção do conhecimento. Ele oportuniza condições ao participante para expressar suas idéias, contrária à imagem do objeto caracterizado como, ferramenta de conceitos prontos e acabados.

Constatamos também, o objeto de aprendizagem como ferramenta de apoio, desperta a interação entre os participantes, onde tempo e espaço são variáveis, não impedindo que os mesmos possam apresentar mudanças em suas reflexões, a partir do pensamento do outro. Essa possibilidade não foi testada nesta versão do objeto, sugerindo alternativas de uso.

Acreditamos que a construção, a testagem e a análise do objeto de aprendizagem trouxeram contribuições tanto para os autores como ao grupo de professores participantes. Nesse contexto podemos ressaltar, que a aprendizagem se dá a partir de interações diversas, onde o sujeito está aprendendo sempre, ou seja, ele é um ser inacabado.

\section{Referências Bibliográficas}

Alava, Séraphin. Os paradoxos de um debate: ciberespaço e formações abertas. Org. Séraphin Alava; trad. Fátima Murad - Porto Alegre: Artmed, 2002.

ASSMANN, Hugo. Reencantar a educação: rumo à sociedade aprendente. Petrópolis-RJ: Vozes, 1998.

BECKER, Fernando. A origem do conhecimento e a aprendizagem escolar. Porto Alegre-RS: Artmed, 2003. 
BECKER, Fernando. Educação e construção do conhecimento. Porto Alegre-RS: Artmed, 2001.

BEN, Vânia. Interação usuário-hipertexto em curso on-line. In: VI CONGRESO DE LINGÜÍSTICA GENERAL, 5., 2004, Universidad de Santiago de Compostela. (no prelo).

CONSTANTINO, Gustavo D. Presenza vitale contro presenza virtuale: studio contrastivo dei modi strategico-discorsivi della interazione didattica. In: BANZATO, $M$. Apprendere in rete. Torino: UTET, 2002.

MARTínez, Ruben A. Lima. O planejamento educacional no sistema estadual de educação (sec) no Rio Grande do Sul. Universidad Pontificia de Salamanca: Salamanca, 1998. Tese de Doutorado.

Mondragón, Salvador Donés. Aportaciones de la semántica del producto al diseño de productos orientados al usuario. Expansión del area de expresión gráfica en Internet. In: XIV CONGRESO INTERNACIONAL DE INGENIERÍA GRÁFICA. Universidad de Cantabria. Santander. Disponível em http://departamentos.unican.es/digteg/ingegraf/cd/ponencias/317.pdf. Acesso em: 10 de novembro de 2006.

MORAN, J. M. Novas tecnologias e o reencantamento do mundo. Revista Tecnologia Educacional. Rio de Janeiro-RJ. Vol 23 n.126, setembro-outubro, 1995. p. 24-26.

NEDER, Maria Lúcia Cavalli e LESSNAU, Remy. Tópicos especiais em EAD. PORGRAD/NEAD/Capacitação de Tutores em EAD. Curitiba-PR, 1999.

PIAGET, Jean. O Nascimento da Inteligência na Criança. Rio de Janeiro-RJ: Livros Técnicos e Científicos Editora, 1987.

PALOFF, Rena M.; PRATT, Keith. O Aluno Virtual - Um Guia para Trabalhar com Estudantes On-line. Porto Alegre-RS: Artmed, 2004. 